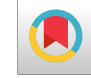

\title{
A Preliminary Study of Tongue Prints for Biometric Authentication
}

\author{
Swapna Bettanapalya Venkatesh (10 ${ }^{1}$, Vignesh Kamath ${ }^{1,{ }^{*}}$, Norhaswani Binti Hasbullah ${ }^{2}$, Noor Syafiqah \\ Syahirah Binti Abdul Mutalib ${ }^{2}$, Muhammad Saiful Bin Mohamad Nazeri ${ }^{2}$, Ahnaf Safiy Bin Malik \\ Putera $^{2}$, Mayasimiriti A/P NKS Tharmaseelan ${ }^{2}$, Jordana Paula ${ }^{2}$ and Sofia Teoh Li Yi ${ }^{2}$ \\ ${ }^{1}$ Department of Prosthodontics, Faculty of Dentistry, Melaka Manipal Medical College, Manipal Academy of Higher Education, Manipal, India \\ ${ }^{2}$ Faculty of Dentistry, Melaka Manipal Medical College, Melaka, Malaysia \\ "Corresponding author: Department of Prosthodontics, Faculty of Dentistry, Melaka Manipal Medical College, Manipal Academy of Higher Education, Manipal, India. Tel: \\ +91-9036979107, Email: vignesh.kamath@manipal.edu
}

Received 2019 July 09; Accepted 2019 August 04.

\begin{abstract}
Background: Several biometric systems like fingerprints, voice scan, iris scan, and palm scan are currently in use. Biometric authentication is an essential process to identify and verify any person for safety reasons. Tongue print is a new method for biometric identification that is unique and cannot be copied easily.

Objectives: This study aims to assess the tongue morphological features and its variations regarding gender and different ethnicities.

Methods: The study sample included two hundred fifty participants. Visual examination of the tongue was done, followed by capturing digital photographs. The photographs were analyzed for the surface morphological features like tongue shape, the presence of fissures, and its distribution pattern. The shape of the tongue was determined by considering three reference points.

Results: Central fissures are the most common feature seen on the dorsal surface of the tongue. The shallow fissure is more common than deep fissures. Females had a higher number of both deep and shallow fissures when compared to males. $U$ shaped were common in males (52.6\%) than females (40.6\%), while V-shaped was more in females (56.1\%). A significant proportion of Malay race has a U-shaped tongue; meanwhile, V-shaped is predominantly found in Indian race.

Conclusions: Tongue prints may constitute secure methods for forensic dentistry identification. The tongue can be a real proof of life as it is unique, and there are no two tongues with similar shape and texture. Lingual morphological aspects are difficult to copy and display stability over time.
\end{abstract}

Keywords: Tongue, Tongue Fissure, Biometric Identification

\section{Background}

The tongue is a muscular organ enclosed in the oral cavity, well protected from the external environment. It is a vital organ, which does multiple functions such as the formation of food bolus, articulation of speech and, taste perception. It is bounded by palate on the superior aspect, floor of the mouth on the inferior aspect, mandibular teeth on the lateral aspects, the pharyngeal region on the posterior aspect, and the lips in anterior aspect (1). The geometric shape of the tongue is generally constant, and the physiological surface texture does not differ much (2). The tongue is an organ that can be easily exposed for inspection and also well protected from environmental influences besides very difficult to manipulate or forge, unlike other identification systems (3).

In biometric authentication, the input sample is compared with a sample template to identify the person. Nowa- days, different biometric methods like fingerprint, palm print, iris scan, signature scan, etc., are in use (4). Each of these systems has its advantages and disadvantages. The drawbacks of each system make it susceptible to a security breach. Fingerprints are the most commonly used biometric authentications, but they can change due to surgery or can be eroded and subjected to injuries and burns. A retinal scan is highly sensitive and can be affected in cases of diseases such as cataracts and astigmatism. Skin color can also be used for biometrics, but it presents with a problem as considerable differences are seen with age, burns, diseases, and use of skin creams or medications $(5,6)$.

Tongue print is the information carried on the exposed portion of the tongue that is the shape and texture altogether. The use of tongue print has several advantages over other biometric systems such as fingerprint, palm scan, and retinal scan (7). The tongue is unique to every person, 
its shape remains consistent and has invariable surface textures. The color, shape, and surface features are exclusive to every person and is further proven by the fact that there is no resemblance of tongue prints even between identical twins (8). It is not affected by external factors as it is well protected. In recent years, a lot of research is being done with the tongue as an important tool in biometric authentication. Liu et al. in 2007, were the first to propose a tongue print recognition system (9). Bade et al. also proposed tongue recognition systems based on $2 \mathrm{D}$ dual-tree complex wavelet (10).

A lingual impression is the impression of the dorsal surface of the tongue along with the lateral borders. This will be useful in determining the shape and the surface characteristics of the tongue. This system of identification is still in the budding stage, with very few studies done. Visual inspection and digital photography have been the time-tested methods adopted in most of the studies.

\section{Objectives}

This study aimed to determine the most common tongue features, its predominant shape, and variations in males and females and different ethnic origins.

\section{Methods}

A total of two hundred and fifty Malaysian dental students participated in the study. The ethical approval for this study (IEC code: 157/2018) was obtained from the Institutional Ethics Committee of Kasturba Medical College, Manipal. The exclusion criteria were students with smoking habits and any history of systemic illness. Informed consent was obtained, followed by clinical examination of the tongue. Before the examination, the subjects were asked to rinse the mouth gently with water to remove any surface debris or food particles. Then, the subjects were asked to protrude the tongue for the observers to analyze and to take a picture of the tongue. After clinical examination, photographs (front view) were taken from a predetermined distance using a digital single length reflex (DSLR) camera. The photographs were compared in terms of morphological features such as shape, depth, and characteristics of fissures by two independent observers. The shape of the tongue was determined by using three points for reference. The reference points included the region of the tongue in contact with the commissure of the lips (when protruded outside the mouth) and the tip of the tongue, as shown in Figure 1.

\section{Results}

A total of two hundred and fifty students participated in the study. Fissures were the most common surface textural characteristic that was observed on visual inspection in the participants. It is observed that shallow fissure (69.2\%) is more common than deep fissures (30.8) (Table 1). Females have a higher number of both deep (62.3\%) and shallow (61.8\%) fissures compared to males as seen in Table 2. In comparison to three different ethnic origins, deep fissure (35.8\%) was found highly significant in the Indian race, followed by Chinese (31.3\%). While the Malay race (75.7\%) showed dominant shallow fissures and less deep fissures. No statistically significant difference was observed between the depth of the fissures and ethnicity, as seen in Table 3.

\begin{tabular}{|cc|}
\hline Table 1. Distribution of Variables & \\
\hline Variables & Values \\
\hline Gender & \\
\hline Males & $38(95)$ \\
\hline Females & $62(155)$ \\
\hline Ethnicity & \\
\hline Indian & $32.4(81)$ \\
\hline Malay & $28(70)$ \\
\hline Chinese & $39.6(99)$ \\
\hline Shape of tongue & \\
\hline U-shaped & $45.2(113)$ \\
\hline V-shaped & $50(125)$ \\
\hline Other & $4.8(12)$ \\
\hline Depth of fissure & $30.8(77)$ \\
\hline Deep & $69.2(173)$ \\
\hline Shallow & \\
\hline
\end{tabular}

${ }^{\mathrm{a}}$ Values are expressed as No. (\%).

\begin{tabular}{ccccc}
\hline \multicolumn{2}{c}{ Table 2. Gender Wise Distribution $^{\mathrm{a}, \mathrm{b}}$} & & \\
\hline & \multicolumn{2}{c}{ Depth } & Chi Value & $\begin{array}{c}\text { P } \\
\text { Value }\end{array}$ \\
\cline { 2 - 4 } & Deep & Shallow & & $0.942^{\mathrm{c}}$ \\
\hline Gender & & & 0.005 & \\
Males & $37.6(29)$ & $62.3(48)$ & & \\
Females & $38.2(66)$ & $61.8(107)$ & & \\
\hline
\end{tabular}

${ }^{\mathrm{a}}$ Values are expressed as No. (\%).

${ }^{\mathrm{b}}$ Level of significance at $\mathrm{P}<0.05$

${ }^{\mathrm{c}}$ Not significant.

About the location of the fissures, fissures were not observed in $3.6 \%$ of the participants. Single pattern fissures 

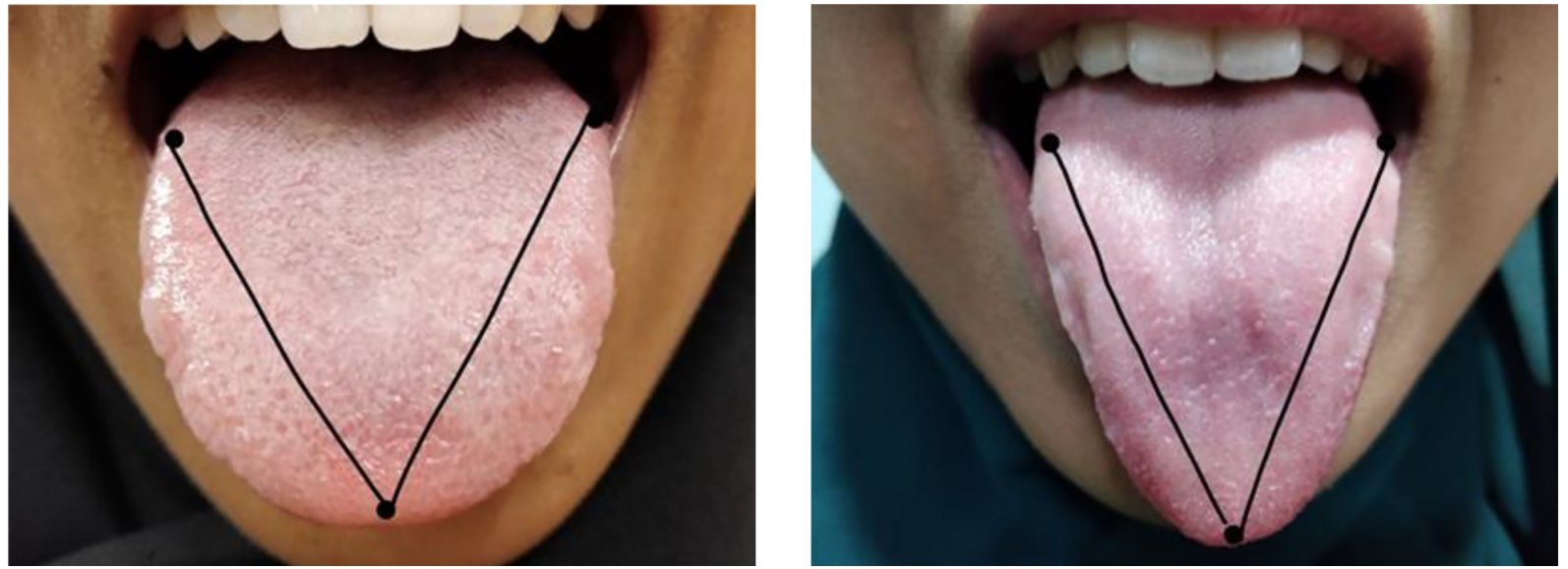

Figure 1. Reference points for determining the shape of the tongue are shown.

\begin{tabular}{ccccc}
\hline Table 3. Depth of Fissure According to Ethnicity & & \\
\hline & \multicolumn{2}{c}{ Depth } & Chi Value & P Value \\
\cline { 2 - 3 } & Deep & Shallow & & \\
\hline Ethnicity & & & 2.35 & $0.308^{\text {b }}$ \\
Indian & $35.8(29)$ & $64.2(52)$ & & \\
Malay & $24.3(17)$ & $75.7(53)$ & \\
Chinese & $31.3(31)$ & $68.7(68)$ & \\
\hline $\begin{array}{l}\text { a Values are expressed as No. (\%). } \\
\text { b Level of Significance at } \mathrm{P}<0.05\end{array}$ \\
\hline
\end{tabular}

were predominant in both males and females (69.2\%) followed by two pattern fissures (26\%) and three or more pattern fissures (1.2\%). For single pattern fissures, central fissure, as well as vertical central fissure, are the most common fissures found in both males and females, which are seen in Table 4.

When analyzing the shape of the tongue, both Ushaped and V-shaped tongue were observed more among females than males and this observation was statistically significant $(\mathrm{P}=0.03)$. Only a small amount of other shaped was observed. U-shaped was common in males (52.6\%) than females (40.6\%) while V-shaped was more common in females (56.1\%) seen in Table 5. A significant proportion of Malay race has a U-shaped tongue (52.9\%); meanwhile, Vshaped is predominantly found in Indian race (54.3\%) seen in Table 6. However, no statistically significant difference was observed that ethnicity plays roles in the variation of shape of the tongue.

\section{Discussion}

With fast advancing technology in recent days, there is a need to prevent impersonation, which requires a fool-

\begin{tabular}{|c|c|}
\hline & Values \\
\hline \multicolumn{2}{|l|}{ Single pattern } \\
\hline $\mathrm{H}$ & $2.4(6)$ \\
\hline MV & $8.4(21)$ \\
\hline $\mathrm{VC}$ & $22.4(56)$ \\
\hline $\mathrm{C}$ & $22.4(56)$ \\
\hline $\mathrm{V}$ & $13.6(34)$ \\
\hline \multicolumn{2}{|l|}{ One or more pattern } \\
\hline $\mathrm{H}+\mathrm{MV}$ & $2.4(6)$ \\
\hline $\mathrm{H}+\mathrm{VC}$ & $1.6(4)$ \\
\hline $\mathrm{H}+\mathrm{C}$ & $0.4(1)$ \\
\hline $\mathrm{H}+\mathrm{V}$ & $2(5)$ \\
\hline $\mathrm{MV}+\mathrm{C}$ & $4.4(11)$ \\
\hline $\mathrm{MV}+\mathrm{VC}$ & $12.4(31)$ \\
\hline $\mathrm{VC}+\mathrm{V}$ & $1.2(3)$ \\
\hline $\mathrm{MV}+\mathrm{V}$ & $1.2(3)$ \\
\hline $\mathrm{VC}+\mathrm{C}$ & $0.4(1)$ \\
\hline \multicolumn{2}{|l|}{ Two or more patterns } \\
\hline $\mathrm{H}+\mathrm{MV}+\mathrm{C}$ & $0.4(1)$ \\
\hline$H+M V+V C$ & $0.8(2)$ \\
\hline \multicolumn{2}{|l|}{ No response } \\
\hline Missing data & $3.6(9)$ \\
\hline
\end{tabular}

Abbreviations: C, central; H, horizontal; MV, multiple vertical; V, vertical; VC, vertical central.

${ }^{\mathrm{a}}$ Values are expressed as No. (\%).

proof biometric tool. Biometric identification of human beings is based on the identification of physiological characteristic parameters. Tongue impression can be a promising biometric tool as the tongue is a unique organ as it varies in each person. Tongue prints cannot be forged eas- 


\begin{tabular}{|c|c|c|c|c|c|}
\hline & \multicolumn{3}{|c|}{ Shape } & \multirow{2}{*}{ Chi Value } & \multirow{2}{*}{ P Value } \\
\hline & U-Shaped & V-Shaped & Others & & \\
\hline Gender & & & & 7.04 & $0.03^{\mathrm{b}}$ \\
\hline Males & $52.6(50)$ & $40(38)$ & $7.4(7)$ & & \\
\hline \multicolumn{6}{|c|}{$\begin{array}{l}{ }^{\mathrm{a}} \text { Values are expressed as No. (\%). } \\
\text { b Level of Significance at } \mathrm{P}<0.05 \text {. }\end{array}$} \\
\hline \multicolumn{6}{|c|}{ Table 6. Shape of the Tongue According to Ethnicity ${ }^{a}$} \\
\hline & \multicolumn{3}{|c|}{ Shape } & Chi Value & P Value \\
\hline Ethnicity & & & & 4.117 & $0.39^{\mathrm{b}}$ \\
\hline Indian & $43.2(35)$ & $52.9(37)$ & $41.4(41)$ & & \\
\hline Malay & $54.3(44)$ & $41.4(29)$ & $52.5(52)$ & & \\
\hline Chinese & $2.5(2)$ & $5.7(4)$ & $6.1(6)$ & & \\
\hline
\end{tabular}

ily. Several methods used to assess morphological features of the tongue include clinical examination, photograph, alginate impression of the tongue, computer algorithm, and sensor. In this study, clinical examination and photographs were used to identify the shape, morphology, and fissures of the tongue. Li and Wei put forward an adaptive segmentation algorithm to section tongue images (9). Various other methods also have been proposed by Stefanescu et al. (11) and Jeddy et al. (12).

In the present study, fissures were predominantly found on the dorsal surface of the tongue. Shallow fissures (69.2\%) were more common than deep fissures (30.8\%). Females have a higher number of both deep (62.3\%) and shallow (61.8\%) fissures compared to males. However, no statistically significant difference was observed between gender and depth of fissures $(\mathrm{P}=0.942)$. The results stated are in agreement with those with Jeddy et al. findings (12) who stated that the difference was not statistically significant. Various patterns of fissures on the dorsum of the tongue like horizontal, multiple vertical, vertical central, central, and vertical fissures are noted. Also, the fissures can be at any location of the dorsum of the tongue and can have more than one pattern and location of an individual. In the present study, single location fissures (69.2\%) were found more on of the dorsum of the tongue, and only $1.2 \%$ had fissures on multiple locations. Central fissure (22.4\%) were more commonly found.

In males, U-shaped (52.6\%) tongue and in females Vshaped were predominantly seen (56.1\%). This observation was statistically significant $(P=0.03)$. These observations were different compared with other studies. The study of Jeddy et al. (12) on Indian population indicated that in both males and females, U-shaped tongue was found predominantly, while females also had a V-shaped tongue with a sharp tip. A significant proportion of Malay race has a Ushaped tongue (52.9\%); meanwhile, V-shaped is predominantly found in Indian race (54.3\%). However, no statistically significant difference was observed that ethnicity plays roles in the variation of the shape of the tongue. With only a few studies on tongue prints, this study may be the pilot study regarding the influence of ethnicity on the shape of the tongue and other morphological features.

\subsection{Conclusions}

The tongue is a unique organ displaying many static and dynamic characteristics, which is unique for every individual. This study represents a preliminary study of tongue features and its variations considering gender and ethnicity. The use of tongue prints as a biometric authentication tool should be further researched as many studies have found it to be beneficial and equivalent to other biometric tools. Studies with large sample size should be done to determine the common morphological tongue features among different gender and ethnic origins to create a database to be used as a biometric tool.

\section{Acknowledgments}

The authors would like to thank all the participants of this study. 


\section{Footnotes}

Authors' Contribution: Swapna Bettanapalya Venkatesh contributed to the design and implementation of the study, literature search, analysis and interpretation of data and involved in drafting the manuscript. Vignesh Kamath contributed to the literature search, analysis and interpretation of data, and revising the manuscript. Norhaswani Binti Hasbullah, Noor Syafiqah Syahirah Binti Abdul Mutalib, and Muhammad Saiful Bin Mohamad Nazeri contributed to conducting the study, data acquisition, and manuscript drafting. Ahnaf Safiy Bin Malik Putera, Mayasimiriti A/P NKS Tharmaseelan, Jordana Paula, Sofia Teoh Li Yi contributed to the literature search and data acquisition.

Conflict of Interests: The authors declare there is no conflict of interest for this study.

Ethical Approval: Ethical approval obtained from the Institutional Ethics Committee of Kasturba Medical College, Manipal dated: 14/3/2018, IEC code: 157/2018.

Funding/Support: Not applicable.

Informed Consent: Informed consent was obtained from all participants prior to the commencement of the study.

\section{References}

1. Zaidi FN, Meadows P, Jacobowitz O, Davidson TM. Tongue anatomy and physiology, the scientific basis for a novel targeted neurostimu- lation system designed for the treatment of obstructive sleep apnea. Neuromodulation. 2013;16(4):376-86. discussion 386. doi: 10.1111/j.15251403.2012.00514.x. [PubMed: 22938390].

2. DentistryIQ Editors. New oral features can be considered unique as a fingerprint. 2014, [cited 2014 Jan 27]. Available from: https://www.dentistryiq.com/clinical/article/16359712/neworal-features-can-be-considered-unique-as-a-fingerprint.

3. Kaur G, Singh D. A novel biometric system based on hybrid fusion speech, signature and tongue. Int J Comput Appl. 2015;119(7):30-9. doi: 10.5120/21082-3764.

4. Zhang DD. Biometric solutions: For authentication in an e-world. 697. Germany: Springer Science and Business Media; 2012. p. 1-21.

5. Bhattacharyya D, Ranjan R, Alisherov F, Choi M. Biometric authentication: A review. Int Jf u e-Serv Sci Technol. 2009;2(3):13-28.

6. Radhika T, Jeddy N, Nithya S. Tongue prints: A novel biometric and potential forensic tool. J Forensic Dent Sci. 2016;8(3):117-9. doi: 10.4103/0975-1475.195119. [PubMed: 28123263]. [PubMed Central: PMC5210096].

7. Maharshi M, Diwakar M. An extraction and recognition of tongueprint images for biometrics authentication system. Int J Comput Appl. 2013;61(3):36-42. doi: 10.5120/9912-4509.

8. Musa OA, Elsheikh TE, Hassona ME. Tongues: Could they also be another fingerprint? Indian J Forensic Med Toxicol. 2014;8(1):171. doi: 10.5958/j.0973-9130.8.1.037.

9. Liu Z, Yan JQ, Zhang DD, Tang QL. A tongue-print image database for recognition. Int Conf Mach Learn Cybern. 2007:2235-8. doi: 10.1109/icmlc.2007.4370517.

10. Bade A, Chavan K, Admane P, Komatwar R. Tongue recognition system for authentication. Int J Res Appl Sci Eng Technol. 2015;3:76-80.

11. Stefanescu CL, Popa MF, Candea LS. Preliminary study on the tonguebased forensic identification. Rom J Leg Med. 2014;22:263-6.

12. Jeddy N, Radhika T, Nithya S. Tongue prints in biometric authentication: A pilot study. J Oral Maxillofac Pathol. 2017;21(1):176-9. doi: 10.4103/jomfp.JOMFP_185_15. [PubMed: 28479712]. [PubMed Central: PMC5406805]. 